\title{
Filtration Efficiency of Air Conditioner Filters and Face Masks to Limit Exposure to Aerosolized Algal Toxins
}

\section{Cassandra J. Gaston ${ }^{1^{* \dagger}}$, Haley M. Royer ${ }^{1 \dagger}$, Raymond J. Leibensperger $\mathrm{III}^{1 \neq}$, Daniela Maizel $^{1}$, Kaycie B. Lanpher ${ }^{1}$, Helena Solo-Gabriele ${ }^{2}$, Larry E. Brand ${ }^{1}$, R. Grace Zhai ${ }^{3}$, Alberto J. Caban-Martinez ${ }^{4}$, Kimberly J. Popendorf ${ }^{{ }^{*}}$}

\author{
${ }^{1}$ Rosenstiel School of Marine and Atmospheric Sciences, University of Miami, Miami, FL, USA \\ ${ }^{2}$ Department of Civil, Architectural, and Environmental Engineering, University of Miami, Coral \\ Gables, FL, USA \\ ${ }^{3}$ Department of Molecular and Cellular Pharmacology, University of Miami, Miller School of \\ Medicine, Miami, FL, USA \\ ${ }^{4}$ Department of Public Health Sciences, University of Miami, Miller School of Medicine, Miami, \\ FL, USA
}

\section{ABSTRACT}

\section{OPEN ACCESS}

Received: January 24, 2021 Revised: April 13, 2021 Accepted: April 20, 2021

\section{${ }^{*}$ Corresponding Authors:}

Cassandra J. Gaston cgaston@rsmas.miami.edu Kimberly J. Popendorf kpopendorf@rsmas.miami.edu

\section{${ }^{\dagger}$ These authors contributed equally to this work}

\section{‡ Present address: Scripps Institution of Oceanography, University of California, San Diego, La Jolla, CA, USA}

\section{Publisher:}

Taiwan Association for Aerosol Research

ISSN: $1680-8584$ print

ISSN: 2071-1409 online

(c) Copyright: The Author(s).

This is an open access article distributed under the terms of the Creative Commons Attribution License (CC BY 4.0), which permits unrestricted use, distribution, and reproduction in any medium, provided the original author and source are cited.
Harmful algal blooms (HABs) can generate toxins that can be aerosolized and negatively impact human health through inhalation. HABs are often found in waterways near residences, therefore, aerosolized $\mathrm{HAB}$ toxins can potentially affect both indoor and outdoor air quality. Given that $\mathrm{HABs}$ are predicted to increase worldwide, effective mitigation strategies are needed to prevent the inhalation of aerosolized HAB toxins. In this work, we characterized both the particle filtration efficiency using particle sizing instruments as well as the mass concentration of different congeners of aerosolized microcystin ( $\mathrm{MC}$ ) toxins that penetrate through commercially available face masks and air conditioner (AC) filters. Particles were generated from cultures of the toxin-producing cyanobacteria Microcystis aeruginosa. Hydrophobic congeners of microcystin including MC-LF and MC-LW were enriched in aerosols compared to water, with MC-LR being the most abundant, which has implications for the toxicity of inhalable particles generated from HAB-contaminated waters. Particle transmission efficiencies and toxin filtration efficiencies scaled with the manufacturerprovided filter performance ratings. Up to $80 \%$ of small, microcystin-containing aerosols were transmitted through AC filters with low filter performance ratings. In contrast, both face masks as well as AC filters with high filter performance ratings efficiently removed toxin-containing particles to below limits of quantification. Our findings suggest that face masks and commercially available AC filters with high filtration efficiency ratings are suitable mitigation strategies to avoid indoor and outdoor air exposure to aerosolized HAB toxins. This work also has relevance for reducing airborne exposure to other $\mathrm{HAB}$ toxins, non-HAB toxins, pathogens, and viruses, including SARS-CoV-2, the virus responsible for the COVID-19 pandemic.

Keywords: Harmful algal bloom, Aerosol, Filter efficiency, Pathogen, Microcystin

\section{INTRODUCTION}

Aerosols are generated from breaking waves and bubbling processes from both the ocean and freshwater systems (Stewart et al., 2008). Both oceans and lakes can be impacted by harmful algal blooms (HABs), some of which produce toxins that can be aerosolized and adversely affect human health (Pierce et al., 2003; Cheng et al., 2007; Erdner et al., 2008; Backer et al., 2010; Brand et al., 2010). Microcystins (MC), a class of hepatotoxins produced by freshwater cyanobacteria, have been shown to be aerosolized both through laboratory and field experiments (Cheng et al., 
2007; Backer et al., 2010; Wood and Dietrich, 2011; Gambaro et al., 2012; Murby and Haney, 2016; Olson et al., 2020). Different congeners of MC display different levels of toxicity (Dawson, 1998; Díez-Quijada et al., 2019). Exposure studies have shown increased sensitivity to MC through inhalation compared to oral ingestion (Codd et al., 1999). Individuals who visit or live near lakes, rivers, and canals impacted by HABs are at risk of both outdoor and indoor exposure to aerosolized $M C$ toxins highlighting the need for adequate methods to limit contact.

Air conditioner (AC) filters and face masks could limit airborne exposure to aerosolized HAB toxins both indoors and outdoors. Common methods of testing mask and filter efficiencies use particle standards and measure either particle number counts or mass concentrations upstream and downstream of filter material (Willeke et al., 1996; Qian et al., 1998; Huang et al., 2007; Jung et al., 2014; Zíková et al., 2015; Serfozo et al., 2017; Drewnick et al., 2020; Konda et al., 2020). For commercially available AC filters, the Minimum Efficiency Reporting Value (MERV) rating or Filter Performance Rating (FPR) reflects the filtering efficiency with increasing MERV or FPR numbers corresponding to filtration of larger fractions of smaller particles down to $0.3 \mu \mathrm{m}$ (Fazli et al., 2019; Hao et al., 2020), The size distributions of aerosolized HAB toxins is unknown but lake spray is known to produce high number concentrations of ultrafine particles (diameter $<0.1 \mu \mathrm{m}$ ) (Olson et al., 2020), which is smaller than the lower limit used for the FPR and MERV rating systems. Further, to our knowledge, no prior filtration efficiency studies have focused on HAB-contaminated lake spray aerosol.

In this work, we simultaneously measured the particle filtration efficiency and determined the toxin filtration efficiency by quantifying individual congeners of $\mathrm{MC}$ in aerosols to evaluate the efficiency of filter materials at removing aerosols relevant for exposure to HAB toxins. Although this study was initiated to evaluate methods to minimize human exposures to aerosols containing $M C$, this work also has relevance for reducing exposure to other $H A B$ toxins, non-HAB toxins, pathogens, and viruses including SARS-CoV-2, the virus responsible for the COVID-19 pandemic (Li et al., 2020; Zhou et al., 2020; Zhu et al., 2020).

\section{METHODS}

\subsection{AC Filters and Face Masks Used}

Six commercially available AC panel filters (labeled Air Filters [AF]) and three types of personal face masks (labeled Face Masks [FM]) were used for experiments (see Table S1 of the Supporting Information (SI) for information regarding the filters). The filters were selected based on three criteria: 1) availability of material information; 2 ) stated performance ratings; 3 ) most importantly, accessibility to the public. For the last criteria, we selected face masks from online merchants and AC filter panels from a home improvement retailer. For criteria 2, the FPR rating system was used. AC filters included: a woven polyester window AC filter (AF1, no FPR provided); HEPA filter with carbon pre-filter (AF2); FPR 4 reusable, washable, multi-layer air panel filter (AF3); FPR 10 high efficiency pleated fiber filter (AF4); FPR 4 pleated fiber filter (AF5); and a FPR 5 electrostatic carbon panel filter (AF6). Face masks included: N95 mask (FM1; 3M model 8210); a disposable surgical mask (FM2); and a medical-grade R95 odor-filtering carbon fiber mask (FM3; 3M model 8247).

\subsection{Particle Generation and Size Distribution Measurements}

Aerosols were generated using a bubbling apparatus (see Fig. 1). Particle-free air (Pall Corporation, in-line HEPA) was split between a porosity $C$ glass frit (25-50 $\mu \mathrm{m}$ pore size) used to bubble a solution to generate aerosols at a flow of 1 liter per minute $\left(\mathrm{L} \mathrm{min}{ }^{-1}\right)$, and a $10 \mathrm{~L} \mathrm{~min}{ }^{-1}$ dilution flow. As shown in Fig. 1, aerosols passed through a filter cassette that was either empty or contained a $47 \mathrm{~mm}$ cutout of a face mask or AC filter-the difference in particle counts when the cassette contained a filter cutout and when it did not was used to determine the particle filtration efficiency. Air flowed across the face mask or AC filter cut-outs at a flow rate of $7.5 \mathrm{~L} \mathrm{~min}^{-1}$, similar to breathing rates at rest (Anthony and Flynn, 2006; Poon and Lai, 2011). At this flow rate, the face velocity across the filter or mask cutout was $\sim 0.07 \mathrm{~m} \mathrm{~s}^{-1}$, similar to velocities used in other mask efficiency experiments (Konda et al., 2020), but lower than typical face velocities across window unit AC filters (Park et al., 2011). Therefore, our reported particle filtration efficiencies for AC filter cutouts are likely upper estimates. The flow that passed across the face mask or AC 


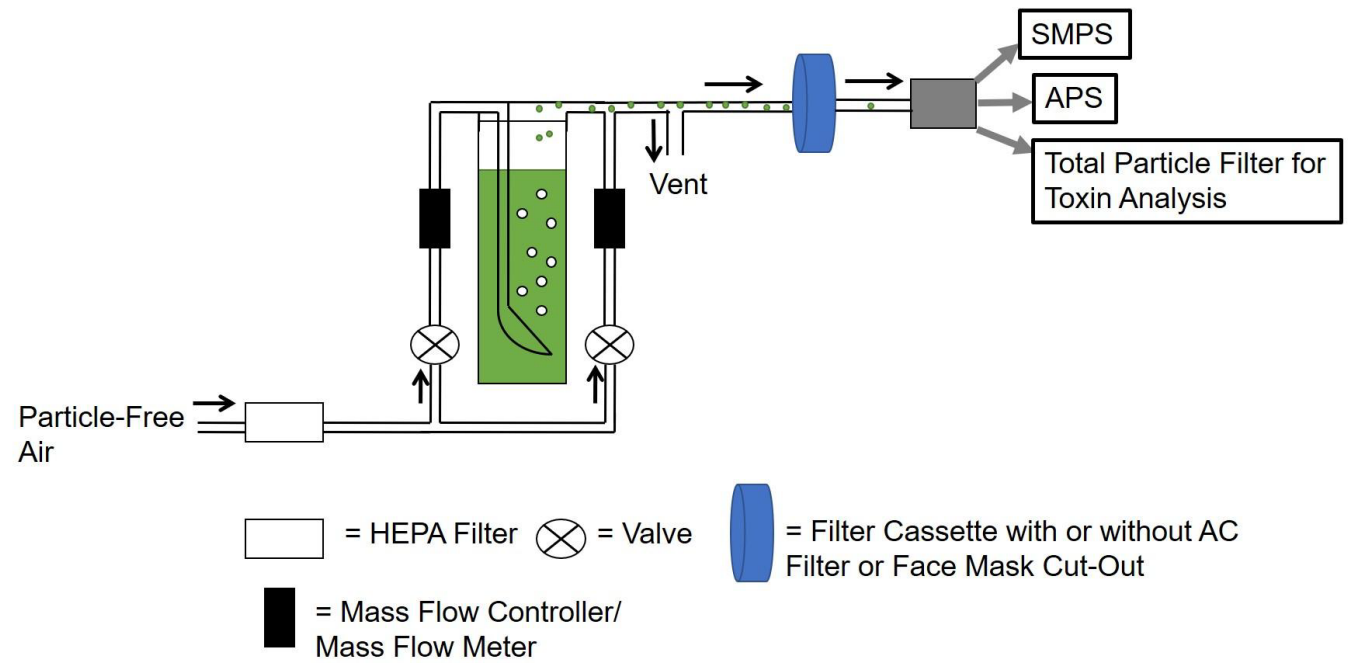

Fig. 1. Schematic of the experimental setup for aerosol generation. Black arrows show the direction of air flow. The filter cassette in blue was used to sample in Mode 1, without a face mask or AC filter cut-out, or in Mode 2, with a face mask or AC filter cut-out, to determine particle filtration efficiencies and toxin filtration efficiencies.

filter piece was at a relative humidity (RH) of $20-30 \%$ for experiments with $\mathrm{HAB}$ cultures and below $60 \%$ for proof-of-concept experiments with seawater. Both values of $\mathrm{RH}$ are near or below typical RHs used to test the filter performance of $A C$ units as recommended by the American National Standards Institute/American Society of Heating, Refrigerating and Air-Conditioning Engineers (ANSI/ASHRAE) and are below average RHs typical of afternoon conditions in South Florida (https://climatecenter.fsu.edu/products-services/data/other-normals/relative-humidity).

The flow was then split to a filter cassette holding a $47 \mathrm{~mm}$ pre-combusted glass fiber filter (EPM2000) as well as particle sizing instruments-a scanning mobility particle sizer (SMPS, model 3082, TSI Inc) and an aerodynamic particle sizer (APS, model 3221, TSI, Inc). The EPM2000 filter was used to collect aerosols for toxin analysis to determine toxin filtration efficiency while the particle sizing instruments collected continuous measurements of the size distribution used to calculate particle filtration efficiencies. Before performing experiments, the bubbling apparatus was tested to verify that the experimental set up was particle-free. The SMPS continuously measured the electrical mobility diameter $\left(\mathrm{d}_{\mathrm{m}}\right)$ in the range of 0.01 to $0.6 \mu \mathrm{m}$ every 5 minutes while the APS continuously measured the aerodynamic diameter $\left(d_{a}\right)$ in the range of 0.5 to $20 \mu \mathrm{m}$ every minute. Size distributions from the combined SMPS and APS data are reported using the physical diameter ( $\left.d_{p}\right)$ (see the SI for additional details) (Khlystov et al., 2004; May et al., 2016).

\subsection{Experiment Design}

Initial, proof-of-concept experiments were performed using filtered seawater obtained from the pier at the Rosenstiel School for Marine and Atmospheric Science (RSMAS) campus (see the SI for details). Experiments were then performed using cultures of Microcystis aeruginosa, a cyanobacteria known to produce cyanotoxins, including different congeners of MC. M. aeruginosa was obtained from a commercial culture collection (Culture Collection of Algae at the University of Texas Austin, UTEX 3037) and maintained under laboratory conditions as a monospecific culture. We then selected three filters representative of high and low filtration efficiencies for experiments with $M$. aeruginosa: FM2 (disposable surgical mask), AF4 (FPR 10), and AF5 (FPR 4). Two experimental runs using FM2 were performed including an exposure to a model animal, the fruit fly Drosophila melanogaster, which is the subject of a companion paper (Hu et al., 2020).

\subsection{Determination of Particle Filtration Efficiencies}

Particle sizing instruments (e.g., SMPS and APS) were used to determine particle filtration efficiencies using two modes of sampling: 1) without a mask or AC filter upstream (Mode 1, empty blue filter cassette in Fig. 1), and 2) with a mask or AC filter upstream (Mode 2, blue filter cassette 
in Fig. 1 contained a filter cut-out). Experiments were performed using continuous size distributions rather than size-selection to simultaneously measure both the number-based particle filtration efficiency of each filter cut-out as well as collect a time-integrated filter used to measure the mass concentration of aerosolized MC toxins removed by each filter cut-out and, thus, determine the toxin filtration efficiency. Continuous particle size data was collected in each Mode for at least 2 hours for experiments with $M$. aeruginosa and 20 minutes for seawater. Experiments were first performed in Mode 1 then in Mode 2. To remove any outliers from particle size distribution data, one iteration of a Grubb's test with a 95\% confidence interval was performed on size distributions collected during experiments using $M$. aeruginosa. SMPS and APS data collected in each sampling Mode were averaged and used to calculate average size-resolved particle filtration efficiencies (F) from Eq. (1):

$F(\%)=\left[1-\frac{\text { Particle Counts in Mode } 2}{\text { Particle Counts in Mode } 1}\right] \times 100 \%$

Eq. (1) was applied to each size bin to determine average size-resolved particle filtration efficiencies. Size bins with poor counting statistics $\left(<5\right.$ particles $\left.\mathrm{cm}^{-3}\right)$ were excluded. We also report composite particle filtration efficiencies averaged across all size bins with uncertainties reported as $95 \%$ confidence intervals calculated using the quadrature rule for error propagation.

\subsection{Toxin Analysis of Water and Air Samples to Determine Toxin Filtration Efficiencies}

Aerosol samples were collected on EPM2000 filters while water samples were collected on 47 $\mathrm{mm}$ combusted glass fiber GF/F filters for toxin analysis. Prior to extraction of water and aerosol filters, leucine enkephalin acetate (ENK, Sigma Aldrich L9133) was added to each sample as an internal standard to check recovery. Each sample was corrected for extraction efficiency using the final amount of ENK on the column per MS run relative to the amount added to the original sample. MC was extracted from both water and air filters via vortexing and sonication in HPLCgrade methanol. Particulate material was removed from samples by filtration with $0.2 \mu \mathrm{m}$ pore size polyethersulfone syringe-tip filters. MC congeners were quantified using reverse phase high pressure liquid chromatography triple quadrupole mass spectrometry (HPLC-MS) using selected reaction monitoring in negative ion mode (Gambaro et al., 2012), with a Dionex 3000 HPLC coupled with a ThermoScientific TSQ Altis triple quadrupole mass spectrometer with electrospray ionization interface. Nine congeners of MC were quantified: microcystin (MC)-LA, MC-LF, MC-LR, MC-LW, MC-LY, MC-RR, MC-WR, MC-YR, and D-Asp-MC-LR. Congener names represent the standard abbreviations for the amino acids at positions two and four in the heptapeptide ring: leucine $(L)$, alanine $(A)$, phenylalanine $(F)$, arginine $(R)$, tryptophan $(W)$, and tyrosine $(Y)$. D-Asp indicates demethylation of the third moiety D-erythro- $\beta$-methylaspartic acid. MC congener analysis used reverse phase chromatography with a Kinetex EVO C18 column (Phenomenex), 150.4.6 mm, $5 \mathrm{~mm}$ particles, $100 \AA$, and a 27 minute chromatography method with a gradient of water with $19 \mathrm{mM}$ ammonium hydroxide (eluent $A$ ) and $80 \%$ methanol, $20 \%$ acetonitrile (eluent $B$ ); all solvents were HPLC-grade (Gambaro et al., 2012). MC were detected with negative ion selected reaction monitoring with typically three transitions for each congener (common precursor ion). MS settings were determined by direct infusion of commercially available standards for each compound of interest, including the 9 congeners of microcystin (Enzo Life Sciences ALX-350-096, ALX-350-081, ALX-350-012, ALX-250-080, ALX-350-148, ALX-350-043, ALX-350-167, ALX-350-044, ALX-250-173).

Instrument response factors for sample quantification were determined for each congener for each sample batch using triplicate analysis of mixed solutions of standards of the nine congeners of interest plus the internal standard at concentrations ranging from 0.5 to $5000 \mathrm{pg}$ on column. The limit of quantification (LOQ) for MC varied by congener, ranging from approximately 20 to $50 \mathrm{pg}$ on column, averaging approximately $45 \mathrm{pg}$ on column across the 9 congeners analyzed. Analytical precision was $\pm 3 \mathrm{pg}$ on column per congener at $50 \mathrm{pg}$ on column, $\pm 14 \mathrm{pg}$ at $500 \mathrm{pg}$ on column, calculated as the average standard error for replicate standard curves across several sample batches. Expected standard error of aerosol samples was calculated based on average 
sample conditions (internal standard recovery and volume of air sampled) and analytical precision at the $\mathrm{pg}$ on column level of the samples, with expected average analytical error for aerosol samples of $0.4 \mathrm{ng} \mathrm{m}^{-3}$.

\section{RESULTS AND DISCUSSION}

\subsection{Proof of Concept Experiments: Filtration Efficiency of Aerosolized \\ Seawater}

The filtration efficiencies (Fig. 2 and Table S2) show a typical U-shaped curve with a minimum in the particle filtration rates between $50-500 \mathrm{~nm}$ due to efficient particle capture by electrostatic forces and diffusion on the lower end of the size distribution and efficient particle capture by inertia on the upper end of the size distribution (Hinds, 1982). Fig S1 in the SI shows average size distributions and Figs. S2 and S3 show the variability of the size distributions collected during the proof-of-concept experiments. The face masks generally had higher filtration efficiencies than the AC filters. Fig. 2(a) shows that face masks commonly used by medical personnel, such as N95 (FM1) and R95 face masks (FM3), had higher filtration efficiencies (e.g., $99 \pm 0.1 \%$ on average) than the disposable surgical mask (FM2, $95 \pm 0.1 \%$ on average), a type of mask worn by both medical personnel and more recently by the public to prevent transmission of the SARS-CoV-2 virus. Notably, the filtration efficiency of FM3 showed no size-dependency while FM1 showed slightly lower filtration efficiency at small sizes between 40-100 nm and FM2 showed a more typical U-shaped curve.

In general, AC filter efficiencies scaled with the FPR number-higher FPR ratings resulted in
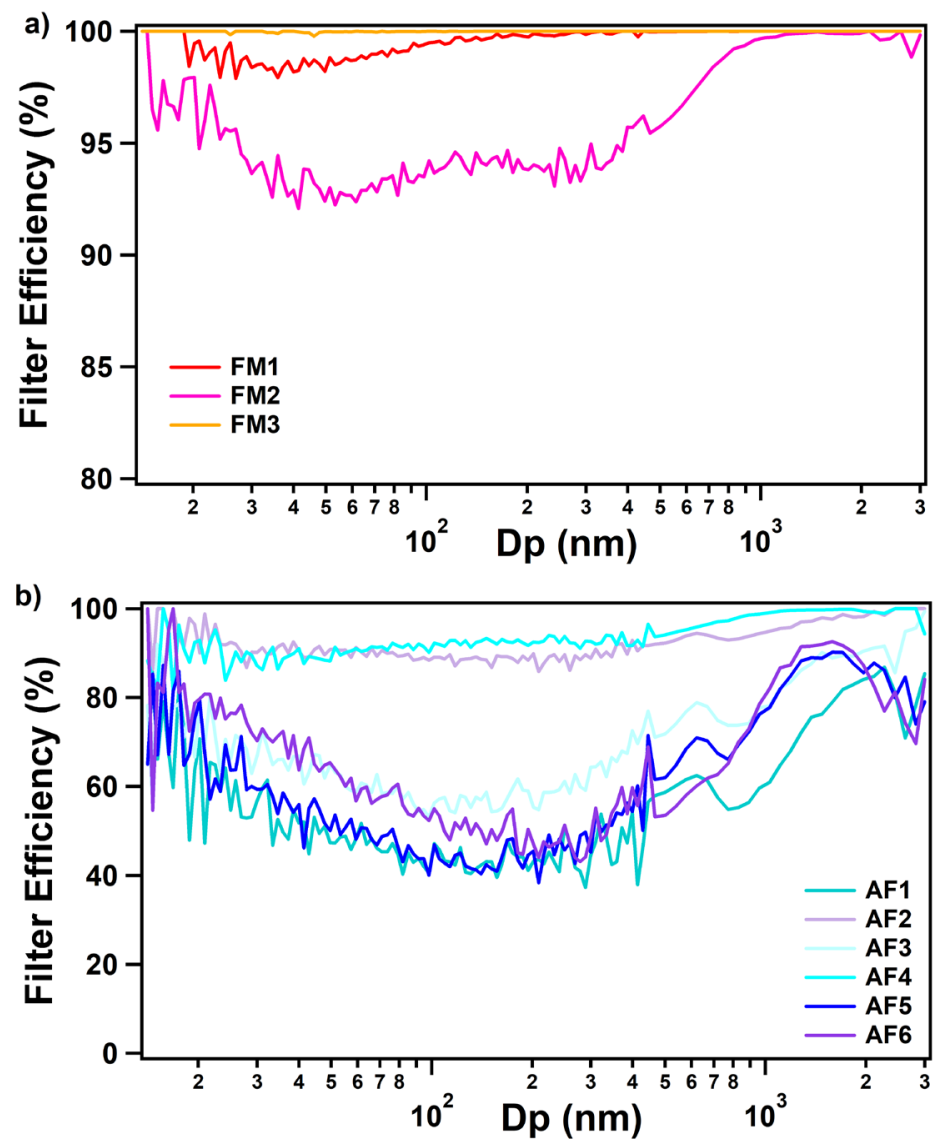

Fig. 2. Average size-resolved particle filtration efficiencies for proof-of-concept experiments using aerosols generated from filtered seawater and (a) three different face mask filter cut-outs (FM; warm colors) and (b) six different air conditioner panel filters (AF; cool colors). Note the different scales for the y-axis in (a) and (b). 
higher filtration efficiencies (see Fig. 2(b)). AF4 had an FPR 10 rating and filtered $92 \pm 1 \%$ of particles, on average, similar to AF2, a high efficiency particulate air (HEPA) filter. Further, filtration efficiencies for AF2 and AF4 also showed a lack of a size-dependence, similar to FM3. In contrast, with ratings of FPR 4, AF5 had an average filtration efficiency of $56 \pm 5 \%$ while AF3 had an efficiency of $65 \pm 3 \%$. AF6 had an FPR rating of 5 and an average filtration efficiency of $62 \pm 4 \%$ while AF1 was an unrated AC panel filter and had an average filtration efficiency of $53 \pm 4 \%$. AF1, AF3, AF5, and AF6 showed strong size-dependent filtration efficiencies as evidenced by the more typical U-shaped curves seen in Fig. 2(b).

\subsection{Filtration Efficiency of Aerosolized HAB Toxins}

The size distributions of aerosols generated from $M$. aeruginosa showed smaller size modes than aerosols generated from filtered seawater ( $42 \mathrm{~nm}$ vs. $85 \mathrm{~nm}$ ) and fewer generated aerosols, consistent with previous work (May et al., 2016). Fig. S4 shows average size distributions and Figs. S5 and S6 show the variability of the size distributions collected during the experiments. Two experiments were conducted with FM2. Consistent with our findings from the seawater experiments, FM2 also showed a slight U-shaped curve and filtered out $97 \pm 1 \%$ of particles generated from $M$. aeruginosa. Both experiments using FM2 produced consistent results in terms of the size-resolved filtration efficiency even though both experiments used separate cultures of M. aeruginosa and were performed months apart from each other (Fig. 3(a), Table 1). Fig. 4 and Table 1 also show the MC toxin data quantified in the cultured water, in aerosols without the inline AF or FM, and in aerosols with the in-line AF or FM. The water concentrations of MC were relatively high, 16-182 $\mathrm{mg} \mathrm{L}^{-1}$, but well within observed $\mathrm{MC}$ concentrations in environmental $\mathrm{HAB}$ conditions (Backer et al., 2010; Díez-Quijada et al., 2019; Olson et al., 2020). The first experiment

a)

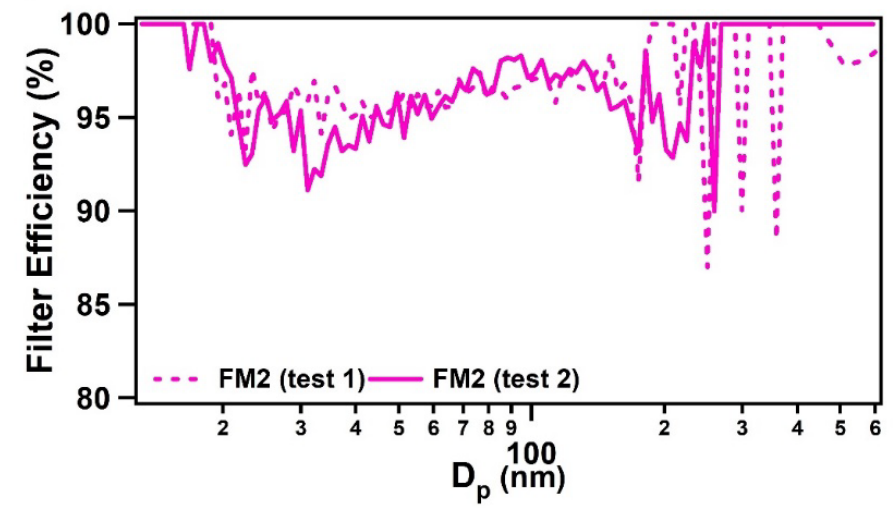

b)

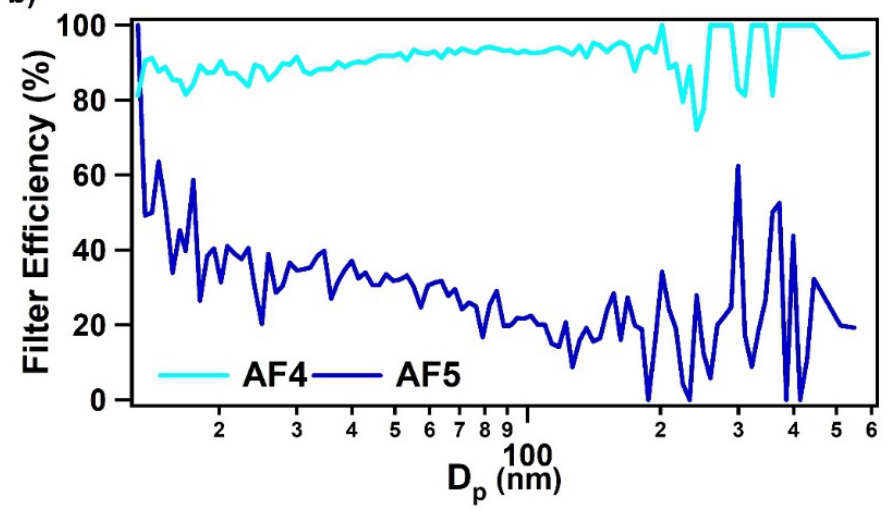

Fig. 3. Average size-resolved particle filtration efficiencies for (a) two tests of a disposable medical face mask (FM2) and (b) two different air conditioner filters (AF4, AF5), tested with HAB aerosol particles. Distributions only extend out to $600 \mathrm{~nm}$ due to limited particle counts at larger sizes. Note the different scales for the $y$-axis in (a) and (b). 


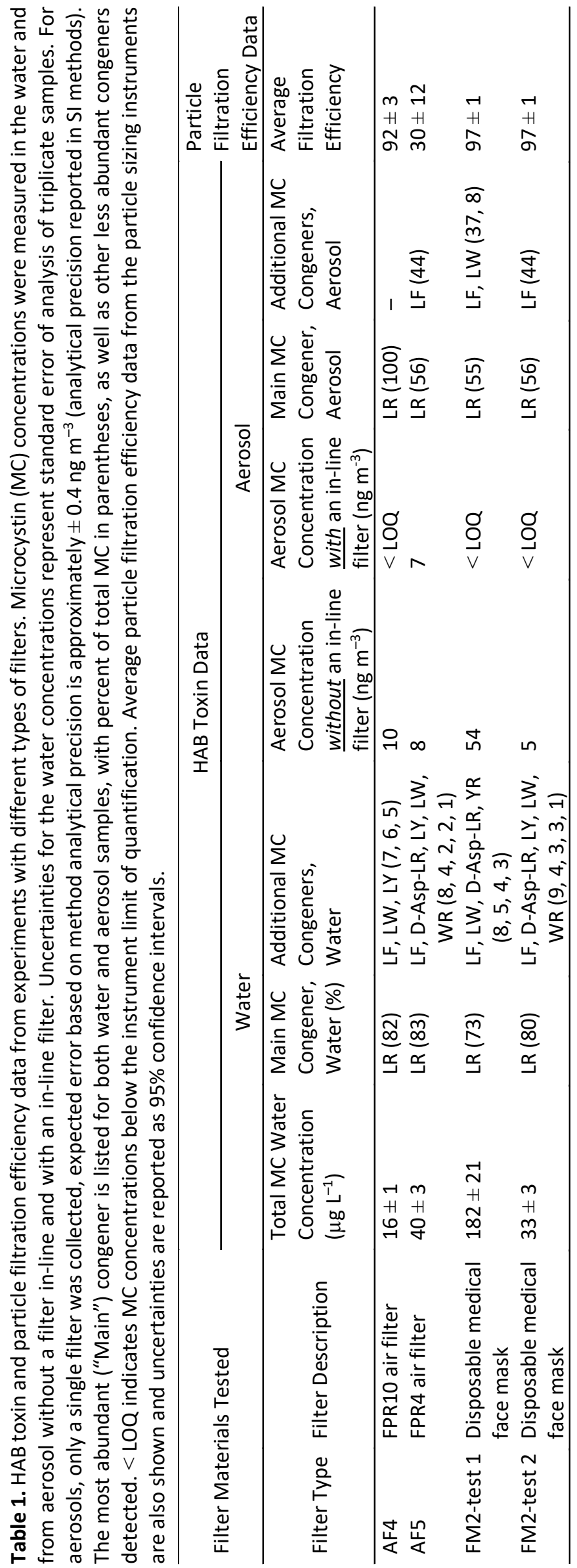




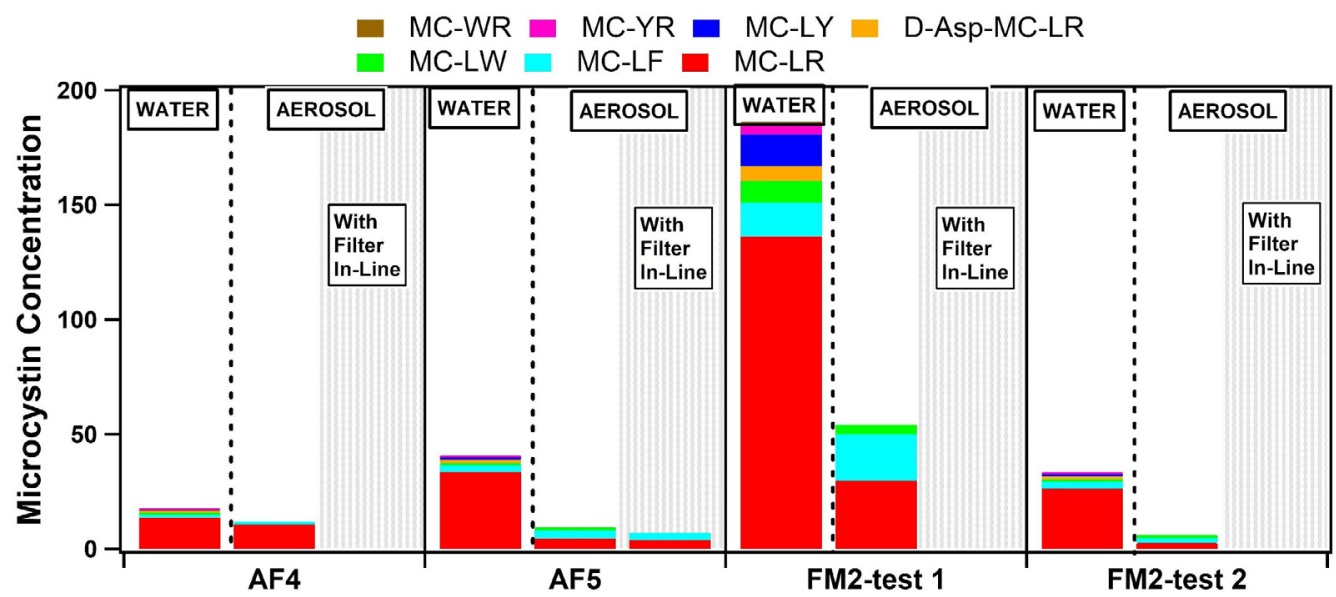

Fig. 4. $M C$ toxin concentrations are shown for water and aerosols generated from solutions of $M$. aeruginosa with and without a filter in-line. Water concentrations are in $\mu \mathrm{g} \mathrm{L}^{-1}$ while aerosol concentrations are in $\mathrm{ng} \mathrm{m}^{-3}$.

with $\mathrm{FM} 2$ had $54 \mathrm{ng} \mathrm{m}^{-3}$ of $\mathrm{MC}$ in the aerosol with no filter in-line while the second experiment with $\mathrm{FM} 2$ had $5 \mathrm{ng} \mathrm{m}^{-3}$ of $\mathrm{MC}$ in the aerosol with no filter in-line. These aerosol concentrations are significantly higher than most reported aerosols from environmental studies (Cheng et al., 2007; Wood and Dietrich, 2011; Gambaro et al., 2012; Murby and Haney, 2016), though at least one environmental study found field aerosol concentrations of MC up to $23 \mathrm{ng} \mathrm{m}^{-3}$ (Backer et al., 2010). In both experiments, the surgical face mask was able to filter out the majority of the particles and reduce aerosolized MC toxin concentrations to below the limit of quantification (LOQ).

In addition to the surgical face masks, experiments were performed with two AC filters (see Fig. 3(b)). AF4 filtered out $92 \pm 3 \%$ of particles on average and did not show a strong sizedependence, in agreement with our seawater experiments (Fig. 3(b) and Table 1). MC concentrations were $10 \mathrm{ng} \mathrm{m}^{-3}$ in the aerosol with no AF4 filter in-line and were completely filtered out by AF4 to below the LOQ (Fig. 4 and Table 1). In contrast, AF5 only filtered out $30 \pm 12 \%$ of aerosol particles, on average, and showed size-dependent particle filtration efficiencies (Fig. 3(b) and Table 1). The much lower particle filtration rate for the aerosols generated from $M$. aeruginosa compared to filtered seawater is likely due to the higher concentrations of smaller, ultrafine particles generated by bubbling cultures of $M$. aeruginosa. The AF5 filter also allowed over $80 \%$ of aerosolized MC toxin to penetrate the filter on average: $M C$ concentrations were $8 \mathrm{ng} \mathrm{m}^{-3}$ in the aerosol with no AF5 filter in-line and $7 \mathrm{ng} \mathrm{m}^{-3}$ in the aerosol with an AF5 filter in-line (Fig. 4 and Table 1).

\subsection{Aerosolization of Individual Microcystin Congeners}

The most abundant MC congener detected both in water and aerosol samples was MC-LR (Fig. 4 and Table 1) - a highly toxic form of MC that is one of the most commonly observed MC congeners in North American HABs (Dawson, 1998; Benson et al., 2005; Díez-Quijada et al., 2019). In addition to MC-LR, minor concentrations of other congeners were quantified in the water including MC-LF, MC-LW, MC-LY, MC-WR, MC-YR, and D-Asp-MC-LR. In aerosol samples, in addition to MC-LR, the only congeners detected were MC-LF and MC-LW, and the relative abundance of congeners in the water and aerosols differed significantly (Fig. 4 and Table 1). In the water, MC-LR was $80 \%$ of the total MC present, on average, but only comprised $56 \%$ of the total MC for three of the four aerosol samples (for the fourth sample, MC-LR was the only congener quantified in the aerosol), with MC-LF and MC-LW making up a much larger fraction of the aerosol MC compared to water MC. For the AF5 experiment, where little of the aerosol MC was removed by the filter, the relative abundance of aerosol congeners was unchanged by the AC filter. MC-LR has been shown to be preferentially enriched in aerosols compared to water due to its hydrophobicity (Olson et al., 2020). MC-LF and MC-LW have been quantified in other environmental HAB aerosol studies (Gambaro et al., 2012), and they are known to be even more hydrophobic than MC-LR (Díez-Quijada et al., 2019) potentially explaining our finding that these two congeners are highly enriched in the aerosol. Although there is less information about the 
toxicity of these minor congeners compared to MC-LR (Testai et al., 2016; Buratti et al., 2017; Díez-Quijada et al., 2019), there is some indication that MC-LF and MC-LW may be more toxic than MC-LR and have neurotoxic effects (Díez-Quijada et al., 2019).

\subsection{Recommendations for Future Studies}

Our work provides key insight into mitigation strategies for exposure to airborne algal toxins. Future studies should determine airborne toxin filtration efficiencies as a function of relative humidity as well as the pressure drop and face velocity across the filter material probed. Such studies would provide insight into the efficacy of different filter material under different AC flow rates and ambient relative humidities. We recommend additional studies that probe size-resolved toxin filtration efficiencies to determine which filters and face masks will prevent exposure to the smallest toxin-containing particles. We also recommend studies that investigate the toxin filtration efficiencies of HAB toxins other than microcystin, such as brevetoxin.

\section{CONCLUSIONS}

The primary contribution of this work is the measurement of toxin capture in conjunction with particle removal efficiencies. Our results indicate that commercially available face masks and AC filter material with high FPR or MERV ratings can efficiently filter aerosolized HAB toxins. As such, this work has implications for improving indoor air quality and limiting outdoor HAB toxin exposure for people who live near water bodies frequently impacted by cyanotoxin-producing HABs. While many filter ratings are for the transmission of particles $0.3 \mu \mathrm{m}$ in diameter or larger and are determined using particle standards, our findings highlight that commercially-available products with high filtration ratings can efficiently filter out even smaller, chemically-complex, toxin-containing particles.

The results of this work also have relevance for aerosolized viruses, including SARS-CoV-2. In the case of SARS-CoV-2, the virus itself has been shown to be $0.06-0.14 \mu \mathrm{m}$ in size (Zhu et al., 2020), within the range of particle sizes studied in this work. Cloth masks and other homemade coverings have been recommended by the Center for Disease Control and Prevention (CDC) for the public to limit the spread of COVID-19 (cdc.gov/coronovirus/2019-ncov). Cloth and homemade masks can be outfitted with a pocket to insert pieces of high-grade filters (Hill et al., 2020; Livingston et al., 2020; Whiley et al., 2020; Zangmeister et al., 2020). The results presented herein can provide clarity on the types of commercially available products that can be used to improve indoor air quality and be inserted into the pockets of cloth masks to limit exposure to aerosolized $\mathrm{HAB}$ toxins as well as other microbiological aerosols. Our results therefore contribute to a growing body of literature regarding the filtration efficiency of commercially available materials (Fazli et al., 2019; Drewnick et al., 2020; Hao et al., 2020; Hill et al., 2020; Konda et al., 2020; Whiley et al., 2020; Zangmeister et al., 2020) that can be used by the public to prevent exposure to toxins and other aerosolized pathogens. More filter efficiency data is critically needed for commercially available materials to both protect the public against airborne transmission of toxins and viruses while simultaneously conserving stockpiles of NIOSH-rated N95 masks.

\section{ACKNOWLEDGEMENTS}

We acknowledge funding from the Florida Department of Health for the project "Diversity and Innovation in Screening and Prevention of Exposure over the Long-term (DISPEL) to HABs" as well as funding from the University of Miami's U-LINK (University of Miami Laboratory for INtegrative Knowledge) program. We thank Albert Ortiz for help with the filter cutting methods. We thank anonymous reviewers for their helpful comments and suggestions that improved this manuscript.

\section{SUPPLEMENTARY MATERIAL}

Supplementary material for this article can be found in the online version at https://doi. org/10.4209/aaqr.210016 


\section{REFERENCES}

ANSI/ASHRAE Standard 52.2-2017. Method of Testing General Ventilation Air-Cleaning Devices for Removal Efficiency by Particle Size. https://www.ashrae.org/

Anthony, T.R., Flynn, M.R. (2006). Computational fluid dynamics investigation of particle inhalability. J. Aerosol Sci. 37, 750-765. https://doi.org/10.1016/j.jaerosci.2005.06.009

Backer, L.C., McNeel, S.V., Barber, T., Kirkpatrick, B., Williams, C., Irvin, M., Zhou, Y., Johnson, T.B., Nierenberg, K., Aubel, M., LePrell, R., Chapman, A., Foss, A., Corum, S., Hill, V.R., Kieszak, S.M., Cheng, Y.S. (2010). Recreational exposure to microcystins during algal blooms in two California lakes. Toxicon 55, 909-921. https://doi.org/10.1016/j.toxicon.2009.07.006

Benson, J.M., Hutt, J.A., Rein, K., Boggs, S.E., Barr, E.B., Fleming, L.E. (2005). The toxicity of microcystin LR in mice following 7 days of inhalation exposure. Toxicon 45, 691-698. https://doi.org/10.1016/j.toxicon.2005.01.004

Brand, L.E., Pablo, J., Compton, A., Hammerschlag, N., Mash, D.C. (2010). Cyanobacterial blooms and the occurrence of the neurotoxin, beta-N-methylamino-l-alanine (BMAA), in South Florida aquatic food webs. Harmful Algae 9, 620-635. https://doi.org/10.1016/j.hal.2010.05.002

Buratti, F.M., Manganelli, M., Vichi, S., Stefanelli, M., Scardala, S., Testai, E., Funari, E. (2017). Cyanotoxins: Producing organisms, occurrence, toxicity, mechanism of action and human health toxicological risk evaluation. Arch. Toxicol. 91, 1049-1130. https://doi.org/10.1007/s00 204-016-1913-6

Centers for Disease Control and Prevention (CDC) (2020). Coronavirus Disease 2019 (COVID-19), https://www.cdc.gov/coronavirus/2019-ncov/index.html?CDC_AA_refVal=https\%3A\%2F\%2F www.cdc.gov\%2Fcoronavirus\%2Findex.html (accessed 2 December 2020).

Cheng, Y., Yue, Z., Irvin, C., Kirkpatrick, B., Backer, L. (2007). Characterization of aerosols containing microcystin. Mar. Drugs 5, 136-150. https://doi.org/10.3390/md504136

Codd, G., Bell, S., Kaya, K., Ward, C., Beattie, K., Metcalf, J. (1999). Cyanobacterial toxins, exposure routes and human health. Eur. J. Phycol. 34, 405-415. https://doi.org/10.1080/0967 0269910001736462

Dawson, R.M. (1998). The toxicology of microcystins. Toxicon 36, 953-962. https://doi.o $\mathrm{rg} / 10.1016 / \mathrm{S} 0041-0101(97) 00102-5$

Díez-Quijada, L., Prieto, A.I., Guzmán-Guillén, R., Jos, A., Cameán, A.M. (2019). Occurrence and toxicity of microcystin congeners other than MC-LR and MC-RR: A review. Food Chem. Toxicol. 125, 106-132. https://doi.org/10.1016/j.fct.2018.12.042

Drewnick, F., Pikmann, J., Fachinger, F., Moormann, L., Sprang, F., Borrmann, S. (2020). Aerosol filtration efficiency of household materials for homemade face masks: Influence of material properties, particle size, particle electrical charge, face velocity, and leaks. Aerosol Sci. Technol. 55, 63-79. https://doi.org/10.1080/02786826.2020.1817846

Erdner, D.L., Dyble, J., Parsons, M.L., Stevens, R.C., Hubbard, K.A., Wrabel, M.L., Moore, S.K., Lefebvre, K.A., Anderson, D.M., Bienfang, P., Bidigare, R.R., Parker, M.S., Moeller, P., Brand, L.E., Trainer, V.L. (2008). Centers for Oceans and Human Health: A unified approach to the challenge of harmful algal blooms. Environ. Health 7, S2. https://doi.org/10.1186/1476-069X7-S2-S2

Fazli, T., Zeng, Y., Stephens, B. (2019). Fine and ultrafine particle removal efficiency of new residential HVAC filters. Indoor Air 29, 656-669. https://doi.org/10.1111/ina.12566

Florida Climate Center (2021). https://climatecenter.fsu.edu/products-services/data/othernormals/relative-humidity (accessed 30 March 2021).

Gambaro, A., Barbaro, E., Zangrando, R., Barbante, C. (2012). Simultaneous quantification of microcystins and nodularin in aerosol samples using high-performance liquid chromatography/negative electrospray ionization tandem mass spectrometry. Rapid Commun. Mass Spectrom. 26, 1497-1506. https://doi.org/10.1002/rcm.6246

Hao, W., Parasch, A., Williams, S., Li, J., Ma, H., Burken, J., Wang, Y. (2020). Filtration performances of non-medical materials as candidates for manufacturing facemasks and respirators. Int. J. Hyg. Environ. Health 229, 113582. https://doi.org/10.1016/j.ijheh.2020.113582

Hill, W.C., Hull, M.S., MacCuspie, R.I. (2020). Testing of commercial masks and respirators and cotton mask insert materials using SARS-CoV-2 virion-sized particulates: Comparison of ideal 
aerosol filtration efficiency versus fitted filtration efficiency. Nano Lett. 20, 7642-7647. https://doi.org/10.1021/acs.nanolett.0c03182

Hinds, W.C. (1982). Aerosol technology: Properties, behaviour, and measurement of airborne particles. $2^{\text {nd }}$ Ed. John Wiley and Sons, New York. 49.

Hu, J., Liu, J., Zhu, Y., Diaz-Perez, Z., Sheridan, M., Royer, H., Leibensperger III, R., Maizel, D. Brand, L., Popendorf, K.J., Gaston, C.J., Zhai, R.G. (2020). Exposure to aerosolized algal toxins in south Florida increases short- and long-term health risk in drosophila model of aging. Toxins, 12, 787. https://doi.org/10.3390/toxins12120787

Huang, S.H., Chen, C.W., Chang, C.P., Lai, C.Y., Chen, C.C. (2007). Penetration of $4.5 \mathrm{~nm}$ to $10 \mu \mathrm{m}$ aerosol particles through fibrous filters. J. Aerosol Sci. 38, 719-727. https://doi.org/10.1016/j. jaerosci.2007.05.007

Jung, H., Kim, J.K., Lee, S., Lee, J., Kim, J., Tsai, P., Yoon, C. (2014). Comparison of filtration efficiency and pressure drop in anti-yellow sand masks, quarantine masks, medical masks, general masks, and handkerchiefs. Aerosol Air Qual. Res. 14, 991-1002. https://doi.org/10.42 09/aaqr.2013.06.0201

Khlystov, A., Stanier, C., Pandis, S.N. (2004). An algorithm for combining electrical mobility and aerodynamic size distributions data when measuring ambient aerosol. Aerosol Sci. Technol. 38, 229-238. https://doi.org/10.1080/02786820390229543

Konda, A., Prakash, A., Moss, G.A., Schmoldt, M., Grant, G.D., Guha, S. (2020). Aerosol filtration efficiency of common fabrics used in respiratory cloth masks. ACS Nano 14, 6339-6347. https://doi.org/10.1021/acsnano.0c03252

Li, Q., Guan, X., Wu, P., Wang, X., Zhou, L., Tong, Y., Ren, R., Leung, K.S.M., Lau, E.H.Y., Wong, J.Y., Xing, X., Xiang, N., Wu, Y., Li, C., Chen, Q., Li, D., Liu, T., Zhao, J., Liu, M., Tu, W., et al. (2020). Early transmission dynamics in Wuhan, China, of novel coronavirus-infected pneumonia. $\mathrm{N}$. Engl. J. Med. https://doi.org/10.1056/NEJMoa2001316

Livingston, E., Desai, A., Berkwits, M. (2020). Sourcing personal protective equipment during the COVID-19 pandemic. JAMA 19, 1912-1914. https://doi.org/10.1001/jama.2020.5317

May, N.W., Axson, J.L., Watson, A., Pratt, K.A., Ault, A.P. (2016). Lake spray aerosol generation: A method for producing representative particles from freshwater wave breaking. Atmos. Meas. Tech. 9, 4311-4325. https://doi.org/10.5194/amt-9-4311-2016

Murby, A.L., Haney, J.F. (2016). Field and laboratory methods to monitor lake aerosols for cyanobacteria and microcystins. Aerobiologia, 32, 395-403. https://doi.org/10.1007/s10453015-9409-z

Olson, N.E., Cooke, M.E., Shi, J.H., Birbeck, J.A., Westrick, J.A., Ault, A.P. (2020). Harmful algal bloom toxins in aerosol generated from inland lake water. Environ. Sci. Technol. 54, 47694780. https://doi.org/10.1021/acs.est.9b07727

Park, J.H., Yoon, K.Y., Hwang, J. (2011). Removal of submicron particles using a carbon fiber ionizer-assisted medium air filter in a heating, ventilation, and air-conditioning (HVAC) system. Build. Environ. 46, 1699-1708. https://doi.org/10.1016/j.buildenv.2011.02.010

Pierce, R.H., Henry, M.S., Blum, P.C., Lyons, J., Cheng, Y.S., Yazzie, D., Zhou, Y. (2003). Brevetoxin concentrations in marine aerosol: Human exposure levels during a Karenia brevis harmful algal bloom. Bull. Environ. Contam. Toxicol. 70, 161-165. https://doi.org/10.1007/s00128-002-0170-y

Poon, C.K.M., Lai, A.C.K. (2011). An experimental study quantifying pulmonary ventilation on inhalation of aerosol under steady and episodic emission. J. Hazard. Mater. 192, 1299-1306. https://doi.org/10.1016/j.jhazmat.2011.06.040

Qian, Y., Willeke, K., Grinshpun, S.A., Donnelly, J., Coffey, C.C. (1998). Performance of N95 respirators: Filtration efficiency for airborne microbial and inert particles. Am. Ind. Hyg. Assoc. J. 59, 128-132. https://doi.org/10.1080/15428119891010389

Serfozo, N., Ondráček, J., Zíková, N., Lazaridis, M., Ždímal, V. (2017). Size-resolved penetration of filtering materials from CE-marked filtering facepiece respirators. Aerosol Air Qual. Res. 17, 1305-1315. https://doi.org/10.4209/aaqr.2016.09.0390

Stewart, J.R., Gast, R.J., Fujioka, R.S., Solo-Gabriele, H.M., Meschke, J.S., Amaral-Zettler, L.A., del Castillo, E., Polz, M.F., Collier, T.K., Strom, M.S., Sinigalliano, C.D., Moeller, P.D., Holland, A.F. (2008). The coastal environment and human health: Microbial indicators, pathogens, sentinels and reservoirs. Environ. Health 7, S3. https://doi.org/10.1186/1476-069X-7-S2-S3

Testai, E., Buratti, F.M., Funari, E., Manganelli, M., Vichi, S., Arnich, N., Biré, R., Fessard, V., 
Sialehaamoa, A. (2016). Review and analysis of occurrence, exposure and toxicity of cyanobacteria toxins in food. EFSA Support. Publ. 13, 998E. https://doi.org/10.2903/sp.efsa.2 016.en-998

Whiley, H., Keerthirathne, T.P., Nisar, M.A., White, M.A.F., Ross, K.E. (2020). Viral filtration efficiency of fabric masks compared with surgical and N95 masks. Pathogens 9, 762. https://doi.org/10.3390/pathogens9090762

Willeke, K., Qian, Y., Donnelly, J., Grinshpun, S., Ulevicius, V. (1996). Penetration of airborne microorganisms through a surgical mask and a dust/mist respirator. Am. Ind. Hyg. Assoc. J. 57, 348-355. https://doi.org/10.1080/15428119691014882

Wood, S.A., Dietrich, D.R. (2011). Quantitative assessment of aerosolized cyanobacterial toxins at two New Zealand lakes. J. Environ. Monit. 13, 1617-1624. https://doi.org/10.1039/C1EM10 $102 \mathrm{~A}$

Zangmeister, C.D., Radney, J.G., Vicenzi, E.P., Weaver, J.L. (2020). Filtration efficiencies of nanoscale aerosol by cloth mask materials used to slow the spread of SARS-CoV-2. ACS Nano 14, 9188-9200. https://doi.org/10.1021/acsnano.0c05025

Zhou, P., Yang, X. Lou, Wang, X.G., Hu, B., Zhang, L., Zhang, W., Si, H.R., Zhu, Y., Li, B., Huang, C.L., Chen, H.D., Chen, J., Luo, Y., Guo, H., Jiang, R. Di, Liu, M.Q., Chen, Y., Shen, X.R., Wang, X., Zheng, X.S., et al. (2020). A pneumonia outbreak associated with a new coronavirus of probable bat origin. Nature 579, 270-273. https://doi.org/10.1038/s41586-020-2012-7

Zhu, N., Zhang, D., Wang, W., Li, X., Yang, B., Song, J., Zhao, X., Huang, B., Shi, W., Lu, R., Niu, P., Zhan, F., Ma, X., Wang, D., Xu, W., Wu, G., Gao, G.F., Tan, W. (2020). A novel coronavirus from patients with pneumonia in China, 2019. N. Engl. J. Med. 382, 727-733. https://doi.org/10.10 56/NEJMoa2001017

Zíková, N., Ondráček, J., Ždímal, V. (2015). Size-resolved penetration through high-efficiency filter media typically used for aerosol sampling. Aerosol Sci. Technol. 49, 239-249. https://doi.org/1 0.1080/02786826.2015.1020997 